OPEN ACCESS

Edited by:

Ilija Djekic,

University of Belgrade, Serbia

Reviewed by:

Vivica I. Kraak

Virginia Tech, United States

${ }^{*}$ Correspondence:

Mirko Ancillotti

Mirko.ancillotti@crb.uu.se

Specialty section:

This article was submitted to

Social Movements, Institutions and

Governance,

a section of the journal

Frontiers in Sustainable Food Systems

Received: 12 December 2021

Accepted: 20 January 2022

Published: 23 February 2022

Citation:

Ancillotti M, Nilsson E, Nordvall A-C and Oljans E (2022) The Status Quo Problem and the Role of Consumers Against Antimicrobial Resistance.

Front. Sustain. Food Syst. 6:834022. doi: 10.3389/fsufs.2022.834022

\section{The Status Quo Problem and the Role of Consumers Against Antimicrobial Resistance}

\author{
Mirko Ancillotti ${ }^{1 *}$, Elin Nilsson ${ }^{2,3}$, Anna-Carin Nordvall ${ }^{4}$ and Emma Oljans ${ }^{5}$ \\ ${ }^{1}$ Centre for Research Ethics and Bioethics, Department of Public Health and Caring Sciences, Uppsala University, Uppsala, \\ Sweden, ${ }^{2}$ Umeå School of Business, Economics and Statistics, Umeå University, Umeå, Sweden, ${ }^{3}$ Centre for Regional \\ Science, Umeå University, Umeå, Sweden, ${ }^{4}$ Department of Business Studies, Uppsala University, Uppsala, Sweden, \\ ${ }^{5}$ Uppsala Global Health Research on Implementation and Sustainability, Department of Women's and Children's Health, \\ Uppsala University, Uppsala, Sweden
}

Antimicrobial resistance occurs when microorganisms survive exposure and proliferate in the presence of therapeutic levels of antimicrobial drugs. Because antimicrobial resistance is increasing, it is vital to encourage consumers to change and adopt smarter antibiotic behaviour. Despite World Health Organization's efforts to combat antibiotic resistance and their emphasis on the importance of public involvement, the role of consumers has been overlooked. The manifold responsibility for antibiotic resistance extends across different actors, including food retailers and consumers. Given this shared responsibility, a blame game arises and no action occurs. To overcome this status quo situation, we draw attention to the potential role of individual responsibility and social pressure to encourage consumers to adopt smart antibiotic behaviour but also to empower them. Conditions must be put in place to enable consumers' critical evaluation of the health-related and ethical aspects of their food choices. Such behaviour can be facilitated using digital innovations to support informed choices, in store and online.

Keywords: consumer behaviour, food retailers, global health, one health, antimicrobial resistance

\section{INTRODUCTION}

Antimicrobial resistance (AMR) occurs when microorganisms such as bacteria, viruses, fungi and parasites survive exposure and proliferate in the presence of therapeutic levels of antimicrobial drugs, such as antibiotics. The use of antimicrobials in food-producing animals and humans is associated with both AMR in bacteria from humans and AMR in bacteria from foodproducing animals (European Centre for Disease Prevention Control (ECDC), 2021). International bodies recommend governments, private-sector actors, and also the public to reduce the use of antimicrobials in both human health and in global food systems (World Health Organization (WHO), 2017, 2021a; European Centre for Disease Prevention Control (ECDC), 2021). The present article focuses on the role of consumers in reducing AMR risks connected with food environments and food systems and does not address AMR in relation to health and medical systems.

Every year, at least 700,000 people die from diseases related to drug-resistant bacteria. This number is estimated to rise dramatically to 10 million and cause a $3.8 \%$ reduction in annual gross domestic product by 2050 (Jonas et al., 2017). AMR is a major sustainability issue (World Health Organization (WHO), 2021b), argued to be comparable in severity and complexity to climate change (Jasovský et al., 2016), which involves questions of global equity, unequal exposure 
to disease risk, etc. (Ancillotti, 2021). Another aspect of the similarity is the complexity of the challenge: Where do we begin and what actions should be highlighted and prioritised? Multifaceted issues require multiple responses that engage actors across a range of disciplines. Even though key international bodies such as the Food and Agriculture Organisation of the United Nations (FAO), the World Organisation for Animal Health (OIE), and the World Health Organisation (WHO) have increasingly framed and addressed AMR as a One Health issue (World Health Organization (WHO), 2015; Food Agriculture Organization of the United Nations (FAO), 2021), ${ }^{1}$ the problem of AMR has not diminished, and cooperation across sectors is still inadequate. One Health is an approach to design and implement local and global programmes, policies, and research characterised by the interaction of multiple sectors to attain optimal health for people, animals and the environment (American Veterinary Medical Association (AVMA), 2008). This increased threat to global health is known and being discussed among experts, but has not gained the attention of consumers it should have.

As mentioned, one of the factors contributing to AMR is food consumption. The use of antibiotics in food production also contributes to the problem of resistant disease in human medicine (Chang et al., 2015; Pokharel et al., 2020). For instance, recent research has shown that high Escherichia coli resistance against penicillin, chloramphenicol, tetracycline, sulfonamides and fluoroquinolones (fundamental antibiotics used in medical settings) is associated with their overuse in poultry animals (Roth et al., 2019).

Although some countries have banned using antibiotics for growth promotion, worldwide this practise, together with disease prevention, still stands for much of the use of antibiotics in animal husbandry (World Health Organization (WHO), 2017, 2021a). Despite international bodies' recommendations to reduce the use of antibiotics in food production (World Health Organization (WHO), 2017, 2021a; European Centre for Disease Prevention Control (ECDC), 2021), the sector is expected to absorb two-thirds of all antibiotics by 2030 (Van Boeckel et al., 2015). The primary audience of these recommendations is policymakers and regulatory officials overseeing food production. Nonetheless, expert bodies underline the important role of consumers as a driving force in the market, in that they influence how foods are produced through their choices (World Health Organization (WHO), 2017). WHO's focus on consumers is part of a wider strategy of public involvement. In 2015, it transformed its global strategy for containment of AMR into action by adopting the Global Action Plan on Antimicrobial Resistance (World Health Organization (WHO), 2015). One of the five main strategic objectives identified by WHO is improving awareness and understanding of AMR through effective communication, education and training.

\footnotetext{
${ }^{1}$ See for instance the 'Webinar on the FAO-OIE-WHO One Health Approach to AMR Mitigation and Safer Food in the Asia-Pacific Region', 29-30 September 2021, New Delhi, India (virtual). Available here: https://www.who.int/southeastasia/ news/events/detail/2021/09/29/south-east-asia-events/webinar-on-the-faooie-who-one-health-approach-to-amr-mitigation- and-safer-food-in-the-asiapacific-region.
}

Accordingly, one way to help deal with AMR is to promote behavioural change, including consumer behaviour. The question, however, is whether consumers can be expected to make smart antibiotic choices concerning food if they lack proper knowledge about AMR.

Generally, consumers' understanding of antibiotic resistance is characterised by misconceptions and low levels of awareness and knowledge. Public knowledge regarding the harms of AMR and its implications is generally limited (Gualano et al., 2014). Consumers often believe that the problem with food is that antibiotic residues remain in foods that have been produced with antibiotics (Redding et al., 2021). That is not the case. Antibiotic resistance spreads through environments in which antibiotics are used (antibiotic pollution) and via the food chain through direct or indirect exposure to resistant bacteria. Even in the case of relatively well-informed consumers, we may ask whether they have any responsibility to minimise their potential contribution to the antibiotic resistance problem when purchasing groceries or whether the responsibility lies elsewhere.

\section{MATERIALS AND METHODS}

On March 16, 2021, we held an online workshop entitled "Consumer Behaviour and Antibiotic Resistance" as part of the 2021 Uppsala Health Summit on AMR (Ancillotti et al., 2021a). The purpose was to explore ways of promoting - through a multi-stakeholder approach - more sustainable purchasing behaviour among consumers. The workshop was attended by 33 participants from all around the world, mainly from European and African countries, but also from the US, Thailand and Australia. Participants had diverse backgrounds and represented different interests, including food and drug authorities, retailers, human and veterinary medicine, patient safety organisations, behavioural research, pharmaceutical companies, and ethics. The workshop had a three folded structure: firstly, three invited speakers gave their talks, each followed by a questions and answers space; secondly, thematic discussions were held in breakout groups around the themes of retailers and consumers' role against antibiotic resistance; thirdly, wrap up and final considerations. One workshop organiser was present in each breakout group to facilitate the discussion and take notes.

\section{RESULTS}

Most workshop participants agreed that consumers have a responsibility for the food they purchase and consume. Such responsibility varies and depends on individual and local contexts. Legislation and social structure pave the way for how consumers can act, what the use of antibiotics in food production looks like and the transparency involved in conveying this information. There was consensus around the notion that the continuous blame game taking place among consumers, producers, retailers and authorities is not conducive to finding solutions, but highlights the interconnection and interdependence of the involved parties. The multiple methods for promoting sustainable consumption behaviour regarding 
antibiotic resistance - such as campaigning, taxation, increasing awareness of the problem, etc. - are not mutually exclusive and need to be tailored to local realities. In turn, local actions need to be supported by a global commitment to reduce the use of antimicrobials. Labelling as a way to inform and promote smart behaviour among consumers was a main topic of discussion. The formulation of this kind of labels, e.g. "antibiotic free" or "organic", can raise different concerns, as there is a need for the information provided to be detailed, effective, comprehensible but not long. "Antibiotic footprint" was suggested as a positive example (Limmathurotsakul et al., 2019). Local actions through partnerships between the private sector and civil society, media, academia and others are required if we are to make a difference in people's lives. Furthermore, participants suggested that retailers could help consumers in their decision-making in several ways. For example, promoting antibiotic-smart goods or providing guidance, e.g., by having clearer information on products or simpler, more comprehensive labels, or by tailoring offerings in online shopping based on stated preferences (e.g., healthier or more animal-friendly products), thereby decreasing stress levels in consumers' decision-making processes.

\section{DISCUSSION}

The workshop showed that different stakeholders believed that the responsibility for antibiotic resistance was manifold and extended across authorities, food producers, consumers, retailers and civil society as a whole. This shared responsibility leads to a status quo situation, where consumers state that if retailers were to offer more antibiotic-smart goods in the grocery store, they would buy these goods. At the same time, the retailers say that if consumers were to buy more sustainable food, they would offer such goods to a greater extent. Moreover, both consumers and retailers feel locked in and limited by the conditions in which producers must operate, somehow forced by the market and the legislation regulating their work. This blame game leads to a paralysing status quo situation. Although inaction is extremely counterproductive as regards curbing antibiotic resistance, the status quo can be shaken up by bottom-up, e.g., conscientious consumerism, and top-down initiatives, e.g., more stringent policies on antibiotic use in food animals. In our view, even worse than the blame game is the idea that the responsibility for producing more sustainable food is a kind of zero-sum game, meaning that if one party holds or assumes more responsibility (typically authorities), then the responsibility of others (producers, retailers, and consumers) diminishes or vanishes (Grill and Nihlén Fahlquist, 2012). This happens either because such responsibility is somehow regarded as a finite entity that can be divided into larger and smaller shares or because, essentially, there is a belief that collective problems can only be handled through top-down initiatives. This, in turn, leads to little trust in the capacity of consumers to engage in judicious behaviours. It is fair to assume that securing antibiotic effectiveness through stewardship and coordinated actions, including regulating food production, is the duty of national governments and international bodies. However, consumers, individually and collectively, have a responsibility to choose, within the boundaries of their political, economic, and socio-cultural contexts, to adopt more sustainable food habits. Through their food choices, consumers can have an impact on decision-makers. In the end, it is the consumers who decide what they do and do not purchase.

Major efforts to change consumer behaviour have been made in relation to sustainability. Punishments, rewards and regulations have typically been used to put pressure on consumers. However, studies show that forced or induced behavioural change is not conducive to long-term change (Van Kleef and Van Trijp, 2018). A relatively underexplored direction involves the possibility of encouraging consumers to display correct antibiotic behaviours by putting social pressure on them, but also by empowering them and making them feel responsible for acting sustainably in their food choices.

The power of engagement should not be underestimated. For example, the attention that the global climate crisis has gained thanks to bottom-up movements may not have resulted in gamechanging international agreements, but such movements have proven to be able to influence or induce pro-environmental consumer behaviour (Roser-Renouf et al., 2016). The antibiotic resistance issue would benefit from a bottom-up movement, which would shed light on AMR-related problems and increase people's commitment to change. For instance, "Antibiotic Off the Menu" is a campaign of Consumers International to put pressure on large international restaurant chains to stop using meat raised with medically important antibiotics (Consumers International, 2022). Initiatives as such, do not only serve the primary declared aim, i.e. reducing the use of antibiotics in food systems, but serve to raise consumers' awareness of the AMR problem and of their role as consumers who can decide where to buy.

It may be argued that changing food behaviour is a matter of getting the packaging of messages right. If this could be accomplished, then consumers would change in response. This reasoning is in line with WHO's Global Action Plan (World Health Organization (WHO), 2015), which highlights the need to emphasise and improve awareness and understanding of AMR through effective communication, education and training. We wish to stress the importance of giving consumers information, but admit that this does not automatically cause them to change their behaviour. There is need to develop a shared understanding of the context, as well as to empower consumers using a pluralistic approach to knowledge, values, skills, and attitudes. The goal being to address the interconnected global challenges of AMR and to be able to navigate and interpret the jungle of information and labelling connected to a broad range of food items. Conditions must be put in place to facilitate consumers' critical evaluation of the health-related and ethical aspects of their food choices, including their influence on the environment and animal wellbeing (Ancillotti et al., 2021b). This entails developing the ability to make informed conscious choices among the available alternatives. We need to find new ways to support informed choices, such as using digital innovations in store and online in order to overcome the status quo situation and enable smart antibiotic behaviour. One example of the digitization development in retail is the application, introduced by one of the market leading retail chains in Sweden, enabling consumers to purchase groceries online, find recipes and current offers in the store and see the products sustainability declaration. With 
the application, it is also possible for consumers to track their grocery shopping, allowing them to recognise their purchase pattern. This may not lead to a behavioural change per se, but could make the consumers more aware of the choices they make in the store. A follow up or an improvement of this digitization development could be an application where consumers receive product alternatives to products considered for purchase, with information about the sustainability (including AMR) "gain" involved if they choose the alternative.

\section{DATA AVAILABILITY STATEMENT}

The original contributions presented in the study are available upon reasonable request to the corresponding author.

\section{REFERENCES}

American Veterinary Medical Association (AVMA). (2008). One health: a new professional imperative. One Health Initiative Task Force Final Report. American Veterinary Medical Association: Schaumburg, IL. Available online at: https://www.avma.org/sites/default/files/resources/onehealth_final. pdf (accessed January 27, 2022).

Ancillotti, M. (2021). Antibiotic resistance: A multimethod investigation of individual responsibility and behaviour. Uppsala: Acta Universitatis Upsaliensis. Available online at: https://www.diva-portal.org/smash/record.jsf? pid=diva2\%3A1520759anddswid=-2347 (accessed January 27, 2022).

Ancillotti, M., Nihlén Fahlquist, J., and Eriksson, S. (2021b). Individual moral responsibility for antibiotic resistance. Bioethics. 36, 3-9. doi: 10.1111/bioe. 12958

Ancillotti, M., Oljans, E., Hassan, T., Horikx, L., and Nordvall, A.-C. (2021a). Consumer behaviour and antibiotic resistance. In: Uppsala Health Summit - Managing Antimicrobial Resistance Through Behavior Change. Uppsala. Available online at: https://www.uppsalahealthsummit.se/our-summits/ summit-2021 (accessed January 27, 2022).

Chang, Q., Wang, W., Regev-Yochay, G., Lipsitch, M., and Hanage, W. P. (2015). Antibiotics in agriculture and the risk to human health: how worried should we be? Evol. Appl. 8, 240-7. doi: 10.1111/eva.12185

Consumers International. (2022). Antibiotics Off the Menu. Available online at: https://www.consumersinternational.org/what-we-do/consumerprotection/food/antibiotics-off-the-menu/ (accessed January 27, 2022).

European Centre for Disease Prevention and Control (ECDC), European Food Safety Authority (EFSA), and European Medicines Agency (EMA). (2021). Third joint inter-agency report on integrated analysis of consumption of antimicrobial agents and occurrence of antimicrobial resistance in bacteria from humans and food-producing animals in the EU/EEA. EFSA J. 19, 6712. doi: $10.2903 /$ j.efsa.2021.6712

Food and Agriculture Organization of the United Nations (FAO). (2021). The FAO Action Plan on Antimicrobial Resistance 2021-2025. Rome, Italy: Food and Agriculture Organization of the United Nations.

Grill, K., and Nihlén Fahlquist, J. (2012). Responsibility, paternalism and alcohol interlocks. Public Health Ethics. 5, 116-127. doi: 10.1093/phe/phs015

Gualano, M. R., Gili, R., Scaioli, G., Bert, F., and Siliquini, R. (2014). General population's knowledge and attitudes about antibiotics: a systematic review and meta-analysis. Pharmacoepidemiol. Drug. Saf. 24, 2-10. doi: 10.1002/pds.3716

Jasovský, D., Littmann, J., Zorzet, A., and Cars, O. (2016). Antimicrobial resistance-a threat to the world's sustainable development. Upsala J. Med. Sci. 121, 159-164. doi: 10.1080/03009734.2016.119 5900

Jonas, O. B., Irwin, A., Berthe, F. C. J., Le Gall, F. G., and Marquez, P. V. (2017). Drug-Resistant Infections: A Threat to Our Economic Future: Final Report (English). Washington, D.C: World Bank Group. Available online at: http:// documents.worldbank.org/curated/en/323311493396993758/final-report

\section{AUTHOR CONTRIBUTIONS}

$\mathrm{MA}, \mathrm{A}-\mathrm{CN}$, and EO contributed to the design of the project, facilitated the workshop, analysed the material and contributed to the writing, reviewing, and editing of the manuscript. EN participated in the workshop, contributed to the writing, reviewing, and editing of the manuscript. All authors approved the submitted version.

\section{ACKNOWLEDGMENTS}

We would like to express our gratitude to the participants and to the organisers of the 2021 Uppsala Health Summit Managing Antimicrobial Resistance Through Behavior Change.

Limmathurotsakul, D., Sandoe, J. A. T., Barrett, D. C., Corley, M., Hsu, L. Y., Mendelson, M., et al. (2019), 'Antibiotic footprint' as a communication tool to aid reduction of antibiotic consumption. J. Antimicrob. Chemother. 74, 2122-2127. doi: 10.1093/jac/dk Z185

Pokharel, S., Shrestha, P., and Adhikari, B. (2020). Antimicrobial use in food animals and human health: time to implement 'One Health' approach. Antimicrob. Resist. Infect. Control. 9, 181. doi: 10.1186/s13756-020-00 847-x

Redding, L. E., Parsons, B., and Bender, J. S. (2021). Educational interventions to address misconceptions about antibiotic residues in milk can alter consumer perceptions and may affect purchasing habits. J. Dairy Sci. 104, 11474-11485. doi: 10.3168/jds.2021-2 0595

Roser-Renouf, C., Atkinson, L., Maibach, E., and Leiserowitz, A. (2016). The consumer as climate activist. Int. J. Commun. 10, 4759-4783. Available online at: https://ijoc.org/index.php/ijoc/article/view/4702/1798

Roth, N., Käsbohrer, A., Mayrhofer, S., Zitz, U., Hofacre, C., and Domig, K. J. (2019). The application of antibiotics in broiler production and the resulting antibiotic resistance in Escherichia coli: a global overview. Poultr. Sci. 98,1791-1804. doi: 10.3382/ps/pey539

Van Boeckel, T. P., Brower, C., Gilbert, M., Grenfell, B. T., Levin, S. A., Robinson, T. P., et al. (2015). Global trends in antimicrobial use in food animals. PNAS. 112, 5649. doi: 10.1073/pnas.150314 1112

Van Kleef, E., and Van Trijp, H. C. M. (2018). Methodological challenges of research in nudging. Method Consumer Res. 1, 229-249. doi: 10.1016/B978-0-08-102089-0.00013-3

World Health Organization (WHO) (2015). Global action plan on antimicrobial resistance. Geneva, Switzerland: World Health Organization. Available online at: https://apps.who.int/iris/bitstream/handle/10665/193736/9789241509763 eng.pdf (accessed January 27, 2022).

World Health Organization (WHO) (2017). WHO guidelines on use of medically important antimicrobials in food-producing animals. Geneva, Switzerland: World Health Organization. Available online at: https://apps.who.int/iris/ bitstream/handle/10665/258970/9789241550130-eng.pdf (accessed January 27, 2022).

World Health Organization (WHO) (2021b). Antimicrobial resistance. Geneva Switzerland: World Health Organization. Available online at: https://www.who. int/news-room/fact-sheets/detail/antimicrobial-resistance (accessed January 27, 2022).

World Health Organization (WHO) (2021a). World leaders and experts call for significant reduction in the use of antimicrobial drugs in global food systems. Geneva, Switzerland: World Health Organization. Available online at: https:// www.who.int/news/item/24-08-2021-world-leaders-and-experts-call-forsignificant-reduction-in-the- use- of-antimicrobial-drugs-in-global-foodsystems (accessed January 27, 2022). 
Conflict of Interest: The authors declare that the research was conducted in the absence of any commercial or financial relationships that could be construed as a potential conflict of interest.

Publisher's Note: All claims expressed in this article are solely those of the authors and do not necessarily represent those of their affiliated organizations, or those of the publisher, the editors and the reviewers. Any product that may be evaluated in this article, or claim that may be made by its manufacturer, is not guaranteed or endorsed by the publisher.

Copyright (c) 2022 Ancillotti, Nilsson, Nordvall and Oljans. This is an open-access article distributed under the terms of the Creative Commons Attribution License (CC $B Y)$. The use, distribution or reproduction in other forums is permitted, provided the original author(s) and the copyright owner(s) are credited and that the original publication in this journal is cited, in accordance with accepted academic practice. No use, distribution or reproduction is permitted which does not comply with these terms. 